\title{
Arthritis in a Child with COVID-19-Related Multisystemic Inflammatory Disease - A Case Report
}

\author{
Philip Johnson $^{1 *}$, Ruth María Eraso Garnica ${ }^{1,2}$ and Gloria María Vasquez Duque \\ ${ }^{1}$ Department of Rheumatology, Universidad de Antioquia, Colombia \\ ${ }^{2}$ Department of Pediatric Rheumatology, Hospital Pablo Tobón Uribe, Colombia
}

\begin{abstract}
The SARS-Cov-2 virus causes a broad range of symptoms, including in the musculoskeletal system. Children who are infected with the virus usually have mild to moderate symptoms but can develop a clinical picture termed "multisystem inflammatory syndrome in children and adolescents with COVID-19 (MIS-C)". Joint involvement in this syndrome is infrequent and poorly characterized. We present what we believe to be the first well-documented case of arthritis of the small joints of the hands in a child with an otherwise typical case of MIS-C and give a short review of the literature.
\end{abstract}

\section{Introduction}

It is becoming increasingly clear that the SARS-Cov-2 virus is a multi-faceted pathogen, causing symptoms ranging from harmless upper respiratory tract infections to life-threatening pneumonia, to a myriad of extra-respiratory manifestations [1]. These include, but are not limited to, cutaneousv [2], neurological [1,3], ocular [4] manifestations, and even sudden sensorineural hearing loss [5]. More recently, the involvement of the joints has also been shown to be part of the spectrum, with patients presenting with acute arthritis [6], postinfectious/reactive arthritis [7], and viral arthralgia [8].

In children initially thought to be spared the severe manifestations of the virus, a distinct clinical picture soon emerged [9], which would later be termed "multisystem inflammatory syndrome in children and adolescents with coronavirus disease-19 (COVID-19)" - (MIS-C) by the World Health Organization [10]. Although it is a multisystemic disease, joint involvement is infrequent and is poorly characterized. Here, we present a three-year-old girl who met the criteria for MIS-C, and who, during hospitalization, presented well-documented arthritis of the small joints of the hands.

\section{Case Presentation}

A three-year-old girl with no significant past medical history, except for obesity and two episodes of pulled elbow in each elbow, presented with four days of high fever accompanied by vomiting, abdominal pain, liquid stools, and lumbar pain. On admission (hospitalization day 1 (HD) 1 ), she was febrile, showed signs of dehydration, and was tachycardiac. There were no meningeal signs, but she was irritable. Laboratory screening showed marked elevation of C-reactive protein (CRP) $(14.9 \mathrm{mg} / \mathrm{dl}$ ), lymphopenia (707 cells/ $\left.\mathrm{mm}^{3}\right)$, slight hyponatremia (132 $\left.\mathrm{mmol} / \mathrm{l}\right)$, normal total white blood cell count $\left(10.100 / \mathrm{mm}^{3}\right)$, slightly elevated neutrophils $\left(7676 / \mathrm{mm}^{3}\right)$, and blood platelets in the lower limit (150.000/ $\left.\mathrm{mm}^{3}\right)$. Hemoglobin $(\mathrm{Hb})$ was in the normal range $(13 \mathrm{~g} / \mathrm{dl})$. Uranalysis was unremarkable. She was tested for dengue, which was negative, as were blood and urine cultures. On HD2, she developed marked conjunctival injection, a polymorph rash, and a strawberry tongue, along with a worsening of the abdominal pain. A polymerase chain reaction (PCR) for Sars-Cov-2 was done, which was positive. Following renewed questioning, the parents specified that ten days earlier all adults in the household had suffered anosmia and ageusia and had felt ill, although no one was tested (Figure 1).

Complementary lab results on this day showed a further elevation of the CRP ( $22 \mathrm{mg} / \mathrm{dl})$, thrombocytopenia (96.000/ $\left.\mathrm{mm}^{3}\right)$, and lymphopenia $\left(1485 / \mathrm{mm}^{3}\right)$, hyponatremia (132 $\mathrm{mmol} / \mathrm{l})$, hypoalbuminemia $(2.8 \mathrm{~g} / \mathrm{dl})$, elevated liver enzymes (Aspartate transferase (AST) $(55 \mathrm{U} / \mathrm{l})$, Alanine transferase (ALT) $(85 \mathrm{U} / \mathrm{l})$, troponins $(69.7 \mathrm{ng} / \mathrm{ml})$, ferritin $(447 \mathrm{mg} /$ $\mathrm{dl}$ ), prolonged thromboplastin time (TP) and International Normalized Ratio (INR) (16.1 and 1.43 respectively), and strongly elevated D-dimers (19.987). Sedimentation rate

*Corresponding author: Dr. Philip Johnson, Fellow, pediatric rheumatology, Department of Rheumatology, Universidad de Antioquia, Colombia, Tel: (+57)-305-365-65-73

Accepted: June 11, 2021

Published online: June 14, 2021

Citation: Johnson P, Garnica RME, Duque GMV (2021) Arthritis in a Child with COVID-19-Related Multisystemic Inflammatory Disease - A Case Report. J Orthop Rheumatism 5(1):90-92 


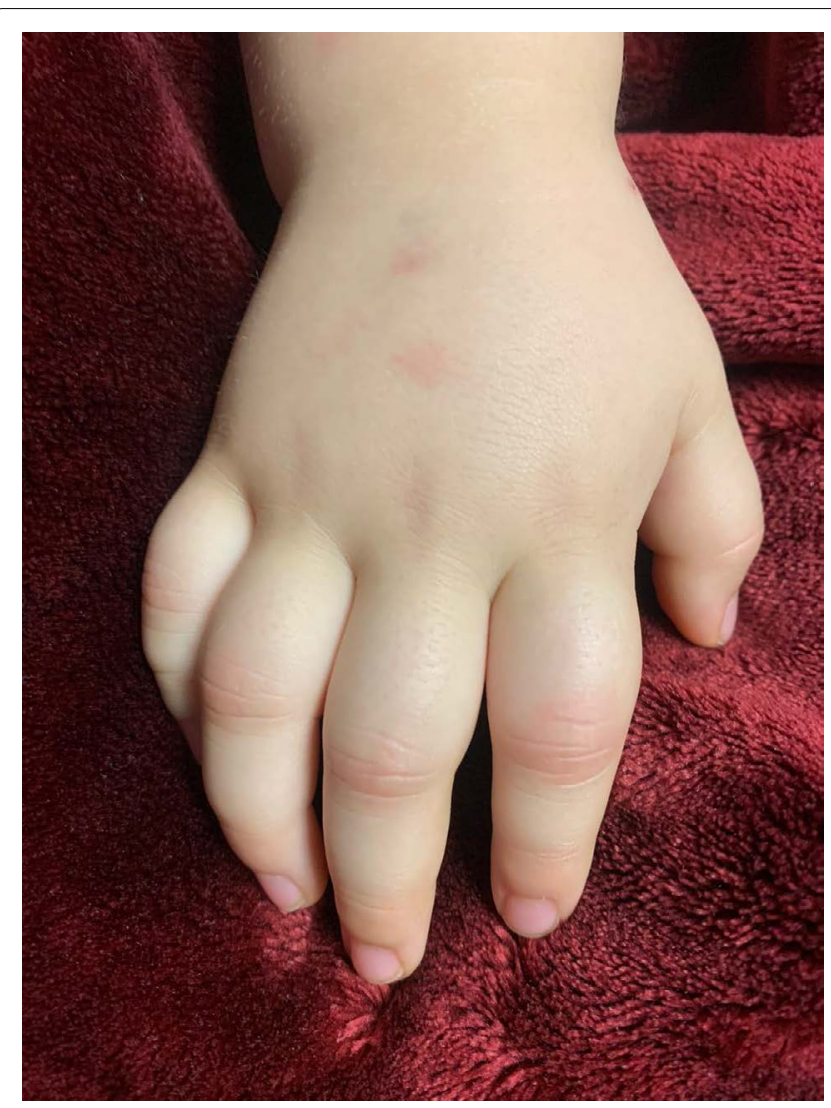

Figure 1: Arthritis involving the proximal interphalangeal joints of the hands with edema, erythema, pain, and severe limitation of movement.

was $12 \mathrm{~mm} / \mathrm{h}, \mathrm{Hb} 11.9 \mathrm{~g} / \mathrm{dl}$, total white blood cells 9900/ $\mathrm{mm}^{3}$, neutrophils $7326 / \mathrm{mm}^{3}$. Thoracic X-ray was normal, and echocardiography showed mild myocardial dysfunction, with a left ventricle ejection fraction (LVEF) of 53\%; there were no coronary dilations. She thus fulfilled the WHO criteria for MIS-C (rash, non-purulent conjunctivitis, features of myocardial dysfunction, evidence of coagulopathy, acute gastrointestinal problems, elevated markers of inflammation, no other obvious cause for the inflammation, evidence of COVID-19) and was started on methylprednisolone $0.8 \mathrm{mg} / \mathrm{kg}$ intravenously every 12 hours, immunoglobulins $2 \mathrm{~g} / \mathrm{kg}$ divided over two days, and was transferred to the pediatric intensive care unit (PICU) because of tachycardia and tachypnea, where she received respiratory support with high-flow cannula. Piperacillintazobactam and vancomycin were started on HD3 due to the respiratory deterioration and persistent diarrhea. On HD4, she developed signs of hypotension, for which she was started on cardiac inotropes, and the high-dosed methylprednisolone was exchanged for three consecutive intravenous pulses with methylprednisolone dosed at $30 \mathrm{mg} / \mathrm{kg}$ (HD 4-6). She was also started on enoxaparin at a prophylactic dose, because of the presence of several risk factors: a central venous catheter, obesity, and the inflammatory syndrome. On HD 4, she presented arthritis limited to several proximal interphalangeal (PIP) joints of both hands, with erythema, edema, and pain, the intensity of which required rescue doses of morphine for 3 days $(1 \mathrm{mg} / \mathrm{kg})$. With the aforementioned treatment, she made a full recovery. She was without fever from HD 4 onward, cardiac inotropes were suspended on HD5, on which day she was transferred to the medical ward, respiratory support was suspended on HD8, and antibiotics on HD11. Lab results at discharge from the hospital on HD12 showed CRP $2.4 \mathrm{mg} / \mathrm{dl}$, Hb 12,1 g/dl, leucocytes 19.800/mm $\mathrm{mm}^{3}$, neutrophils $9306 / \mathrm{mm}^{3}$, lymphocytes $6138 / \mathrm{mm}^{3}$, platelets 390.000/ $\mathrm{mm}^{3}$, AST $24 \mathrm{U} / \mathrm{l}$, ALT $31 \mathrm{UI}, \mathrm{Na} 136 \mathrm{mmol} / \mathrm{l}$. The arthritis in the PIP joints improved over the span of a week and had completely resolved at the time of discharge from the hospital. Enoxaparin was suspended and she was put on aspirin $4 \mathrm{mg} / \mathrm{kg}$ and prednisolone $1 \mathrm{mg} / \mathrm{kg}$, with a schedule for tapering over three weeks. At the last scheduled followup visit five weeks after discharge, the parents stated that she had presented periungual desquamation, and pain and rigidity of the right hip during the week-and-a-half after discharge, with no further complaints of arthritis or other complaints afterwards.

\section{Discussion}

We report a three-year-old child with MIS-Cpresenting with the classical symptoms of rash, non-purulent conjunctivitis, acute gastrointestinal problems, hypotension, myocardial dysfunction, and evidence of coagulopathy, who during her disease presented symmetric arthritis of several proximal interphalangeal joints of the hands. All her symptoms, including the arthritis, responded well to treatment with IVIG and steroid pulses followed by high-dosed steroids, and she made a full recovery.

As the name suggests, MIS-C is a multisystemic disease which has been known to affect almost any system in the body: most commonly the cardiovascular, gastrointestinal, hematological and respiratory systems, and the skin [11-15], but also the central nervous system $[16,17]$. Involvement of the musculoskeletal system has been described much less frequently, and usually presents as myalgia $[11,12,15]$. Joint involvement is even less frequent, and, where described, is poorly characterized with descriptions such as "joint pain", and "arthritis or arthralgia" $[11,15,18]$. Whereas arthritis has been described in the context of COVID-19 infection, to our knowledge none have been in MIS-C, and only one in a minor [7]. Several authors have described a clinical picture of reactive arthritis, with the presentation of arthritis 8 to 25 days after the initial infection $[7,19,20]$ (Parisi - Langhoff). All of these patients had involvement of joints in the lower members, typical for reactive arthritis, although none describe positivity of HLA-B27. Recently, Coath and colleagues described an axial presentation in a 53-old HLA-B27 positive male [21]. Jali describes a patient with arthritis in the small joints of the hands, however, in this case the patient was a 39-year-old woman whose arthritis also presented three weeks after the initial infection, and both the proximal and distal interphalangeal joints were affected. The only minor described above was a 16-year-old girl with dactylitis, also with onset three weeks after the initial infection [7]. There are a few reports of onset of arthritis during the initial phase of the infection. Lopez-Gonzalez and colleagues describe 4 adult male patients with acute arthritis, although three of the four had a history of gout, and the fourth had 
had previous episodes of arthritis, not studied [6]. It can therefore be argued that these patients had acute flares of their preexisting condition. Hoong and colleagues describe 5 patients among 294 patients with COVID-19, who during their illness presented with arthralgia, and they argue that viral arthralgia is a new manifestation [8]. These patients were not, however, described as having objective arthritis.

One of the mechanisms potentially involved in viral arthritis is molecular mimicry, in which certain amino acid sequences found in the SARS-CoV-2 virus may mimic proteins in the synovial membranes [9]. Considering the fact that MIS-C is in essence a postinfectious phenomenom [22], this mechanism is a plausible explanation for our patient's symptoms.

In conclusion, we describe what we believe to be the first well-documented case of acute arthritis in a child with a confirmed diagnosis of MIS-C and with no history of arthritis nor other rheumatologic manifestations. Although there are several reports of documented reactive (or post-viral) arthritis in adults and one in a minor, and even more of viral-induced arthralgia, this report opens up the spectrum of organs potentially being affected in this multisystem inflammatory disease specifically.

\section{Disclaimers any}

Yes, subject to non-profit purpose.

\section{Source and Support}

Self-finance.

\section{Ethical Considerations}

We obtained written consent from the parents of the patient and care was taken not to include elements in the text of picture which could identify the patient.

\section{References}

1. Lai C, Ko W, Lee P, et al. (2020) Extra-respiratory manifestations of COVID-19. Int J Antimicrob Agents 56: 1-6.

2. Gisondi P, Plaserico S, Bordin C, et al. (2020) Cutaneous manifestations of SARS-CoV-2 infection: A clinical update. J Eur Acad Dermatology Venereol 34: 2499-2504.

3. Toscano G, Palmerini F, Ravaglia S, et al. (2020) Guillain-Barré Syndrome associated with SARS-CoV-2. N Engl J Med 382: 25742576.

4. Lawrenson JG, Buckley RJ (2020) COVID-19 and the eye. Ophthalmic Physiol Opt 40: 383-388.

5. Kilic O, Kalcioglu MT, Cag Y, et al. (2020) Could sudden sensorineural hearing loss be the sole manifestation of COVID-19? An investigation into SARS-COV-2 in the etiology of sudden sensorineural hearing loss. Int J Infect Dis 97: 208-211.
6. López-González MC, Peral-Garrido ML, Calabuig I, et al. (2020) Case series of acute arthritis during COVID-19 admission. Ann Rheum Dis 2020-217914.

7. Wendling D, Verhoeven F, Chouk M, et al. (2021) Can SARSCov-2 trigger reactive arthritis? Jt Bone Spine 88.

8. Hoong CWS, Amin MNM, Tan TC, et al. (2020) Viral arthralgia a new manifestation of COVID-19? A cohort study of COVID-19associated musculoskeletal symptoms. Int J Infect Dis.

9. Riphagen S, Gomez X, Gonzalez-Martinez C, et al. (2020) Hyperinflammatory shock in children during COVID-19 pandemic. Lancet 395: 1607-1608.

10. Multisystem inflammatory syndrome in children and adolescents with COVID-19. (2020) World Health Organization.

11. Feldstein LR, Rose EB, Horwitz SM, et al. (2020) Multisystem inflammatory syndrome in U.S. Children and adolescents. N Engl J Med 383: 334-346.

12. Dufort EM, Koumans EH, Chow EJ, et al. (2020) Multisystem inflammatory syndrome in children in New York state. $\mathrm{N}$ Engl J Med 383: 347-358.

13. Godfred-Cato S, Bryant B, Leung J, et al. (2020) COVID-19associated multisystem inflammatory syndrome in children United States, March-July 2020. MMWR Morb Mortal Wkly Rep 69: 1074-1080.

14. Whittaker E, Bamford A, Kenny J, et al. (2020) Clinical Characteristics of 58 Children with a Pediatric Inflammatory Multisystem Syndrome Temporally Associated with SARS-CoV-2. JAMA - J Am Med Assoc.

15. García-Salido A, de Carlos Vicente JC, Belda Hofheinz S, et al. (2020) Severe manifestations of SARS-CoV-2 in children and adolescents: From COVID-19 pneumonia to multisystem inflammatory syndrome: A multicentre study in pediatric intensive care units in Spain. Crit Care 24: 666.

16. De Paulis M, Oliveira DBL, Vieira RP, et al. (2020) Multisystem inflammatory syndrome associated with covid-19 with neurologic manifestations in a child: A brief report. Pediatr Infect Dis J 39: E321-E324.

17. Regev T, Antebi M, Eytan D, et al. (2020) Pediatric Inflammatory Multisystem Syndrome with Central Nervous System Involvement and Hypocomplementemia following SARS-COV-2 Infection. Pediatr Infect Dis J 39: E206-E207.

18. Webb K, Abraham DR, Faleye A, et al. (2020) Multisystem inflammatory syndrome in children in South Africa. Lancet Child Adolesc Heal 4: e38.

19. Parisi S, Borrelli R, Bianchi S, et al. (2020) Viral arthritis and COVID-19. Lancet Rheumatol 2: e655-e657.

20. Hønge BL, Hermansen M-LF, Storgaard M (2021) Reactive arthritis after COVID-19. BMJ Case Rep 14: e241375.

21. Coath FL, Mackay J, Gaffney JK (2021) Axial presentation of reactive arthritis secondary to Covid-19 infection. Rheumatology (Oxford).

22. Conway R, Konig MF, Graef ER, et al. (2021) Inflammatory arthritis in patients with COVID-19. Transl Res.

DOI: $10.36959 / 479 / 438$

Copyright: (C) 2021 Johnson P. This is an open-access article distributed under the terms of the Creative Commons Attribution License, which permits unrestricted use, distribution, and reproduction in any medium, provided the original author and source are credited. 